\title{
Screening for hen's egg and chicken meat specific IgE antibodies in Saudi patients with allergic disorders
}

\author{
Zahid Shakoor, Adel Almogren, Rana Mohammed, \\ Waleed Hasanato, Bushra Zahid
}

Department of Pathology, College of Medicine and University Hospitals, King Saud University

\begin{abstract}
Background: Allergy to hen's egg and meat contributes significantly to the manifestations of food allergy all over the world.

Objectives: This study was performed to assess the presence of hen's egg and meat specific IgE antibodies among patients investigated for various allergic disorders.

Methods. This is a retrospective study performed at King Khalid University Hosptial, Riyadh. Data from 421 patients with allergic disorders screened for food specific IgE antibodies between January 2009 and March 2011 were analyzed. Sixty $(14.25 \%)$ patients including 42 males and 18 females with the mean age (sd) of 7.5 (7.4) years were found to have specific IgE antibodies against hen's egg and chicken meat. There were 56 (93.3\%) children and $4(6.7 \%)$ adult patients. Specific IgE antibodies were measured by radioallergosorbent test (RAST) using Pharmacia ImmunoCAP 250 analyzer.

Results: Atopic dermatitis was the most common (55\%) clinical condition. Out of the total 60 patients harboring hen's egg and chicken meat specific IgE antibodies high levels of egg white, yolk and chicken meat specific IgEs were detected in $58(96.6 \%), 37(61.6 \%)$ and $6(10 \%)$ patients respectively. Both the egg white and yolk antibodies coexisted in $35(58.3 \%)$ patients.
\end{abstract}

Conclusion: Sensitization against hen's egg was higher compared to the chicken meat. Egg white sensitization higher than the egg yolk particularly in Saudi children with food related allergic disorders.

Key words: Allergy, atopic dermatitis, chicken meat, hen's egg, IgE antibodies

DOI:http://dx.doi.org/10.4314/ahs.v14i3.19

\section{Introduction}

Symptoms of food allergy mediated by $\operatorname{IgE}$ antibodies affect approximately $6 \%$ of children and $3.7 \%$ of adults. ${ }^{1}$ Apart from elevated total IgE levels a significantly large proportion of patients with food allergy have been shown to have positive immediate skin prick tests and high levels of specific IgE antibodies to food allergens. ${ }^{2,3}$ The importance of specific $\operatorname{IgE}$ antibodies to food

\section{Corresponding author: \\ Zahid Shakoor. \\ Department of Pathology \\ College of Medicine and University Hospitals \\ King Saud University, \\ PO Box. 2925 \\ Riyadh 11461 \\ Kingdom of Saudi Arabia \\ e-mail: shakoor_zahid@yahoo.com \\ Phone: 00-966-1-4671843 \\ Fax: $\quad 00-966-1-4671842$}

allergens has been well documented in challenge studies where symptoms of food allergy can be reproduced following ingestion of certain foods. In patients with atopic aczema harboring specific IgE antibodies, elimination of incriminated foods from the diet has been shown to be associated with improvement in symptoms. ${ }^{4}$ Since $50 \%$ to $80 \%$ of children with atopic dermatitis also suffer from associated allergic disorders such as asthma and allergic rhinitis ${ }^{5,6}$ elimination of foods that patients are sensitized against may exert a beneficial effect in these disorders as well.

Among the food allergies, allergic reactions to hen's egg are frequent and affect around $1.6 \%$ children at the age of three years. ${ }^{7}$ Although allergy to hen's egg is associated with significant morbidity and is generally believed not to pose a serious threat to life, there are reports of severe anaphylactic reactions following ingestion of eggs along with other food allergies. ${ }^{8}$ The mainstay of the current management of egg allergy along with other allergies is avoidance of exposure as effective treatment for allergy is not available. In the context of egg allergy the extensive use of egg-derived 
components in cooked and manufactured food products it is very difficult to exercise the dietary restrictions. ${ }^{9}$ The two components of hen's egg, the egg white and the yolk have been independently implicated in allergic reactions and specific $\operatorname{IgE}$ antibodies against allergens in the each component can be detected in sensitized individuals. ${ }^{10,11}$ In addition, allergy to chicken meat detected by skin prick test and the presence of specific $\mathrm{IgE}$ antibodies has been shown to exhibit significant cross reactivity with turkey, duck and goose meat. ${ }^{12}$ This study retrospectively examines the radioallergosorbent test (RAST) results for the presence of specific $\operatorname{IgE}$ antibodies against hen's egg and chicken meat among patients attending allergy clinic at King Khalid University Hospital in Riyadh.

\section{Methods:}

\section{Patients and methods}

A total of 578 patients presenting with clinical signs and symptoms suggestive of allergic diseases between January 2009 and March 2011 in the allergy clinic at King Khalid University Hospital were screened for specific IgE antibodies[PT1]. Out of the total number of patients screened $421(73 \%)$ had specific IgE antibodies against various allergens and among them only $60(14.25 \%)$ patients were found to have specific $\mathrm{IgE}$ antibodies against hen's egg and chicken meat. This group of patients included 42 male and 18 female patients with the mean age (sd) of 7.5 (7.4) years (range 1 to 46 years). Among these patients 56 (93.3\%) were children of either equal to or less than 11 years of age and $4(6.7 \%)$ were adults. Only $17(28.3 \%)$ out of the 60 patients could associate exacerbation of their symptoms following ingestion of eggs. The clinical conditions this group of patients presented with included atopic dermatitis, urticaria, gastrointestinal symptoms, asthma and allergic rhinitis.

\section{Measurement of specific IgE.}

Assessment of allergen specific IgE for hen's egg white, yolk and chicken meat was performed by radioallergosorbent test (RAST) using Pharmacia ImmunoCAP 250 analyzer (Phadia, Uppsala, Sweden) in accordance with the recommendations of the manufacturers. Serum samples were dispensed in cups containing allergen coupled to ImmunoCAP. The contents were incubated for 30 minutes and the excess of sample was removed by the machine. Enzyme ( $\beta$-galactosidase generating a fluorescent cleavage product)-labeled anti-IgE antibodies were added and the contents were allowed to react for 30 minutes at $37^{\circ} \mathrm{C}$. Unbound enzyme-anti-IgE was then washed away and the bound complexes were incubated with developing agent (4-methylumbelliferyl-betaD-galactoside) for 10 minutes during which time the substrate underwent cleavage releasing a fluorescing product 4-metylumbelliferon. The reaction was then stopped by adding stop solution and the test response was detected by measuring the fluorescence of the elute. The calibration range for specific $\operatorname{IgE}$ was from 0.1 to $100 \mathrm{kU} / \mathrm{L}$. Result was obtained by transforming the response for the patient samples to concentrations in $\mathrm{kU} / \mathrm{L}$ (kilounits per liter) using the calibration curve. Values lower than $0.35 \mathrm{kU} / \mathrm{L}$ were considered negative. Table 1 shows the interpretation of RAST score from 0 to 6 based on quantitative assessment of the specific $\mathrm{IgE}$ in $\mathrm{kU} / \mathrm{L}$.

Table 1. Interpretation of RAST scores based on quantitative assessment of specific IgE concentration in $\mathrm{kU} / \mathrm{L}$

\begin{tabular}{llllllll}
\hline RAST Test Score (Class) & 0 & 1 & 2 & 3 & 4 & 5 & 6 \\
$\begin{array}{l}\text { Concentration of allergen } \\
\text { specific } \operatorname{IgE}(\mathrm{kU} / \mathrm{L})\end{array}$ & $<0.35$ & $0.35-0.7$ & $0.7-3.5$ & $3.5-17.5$ & $17.5-50$ & $50-100$ & $>100$ \\
\hline
\end{tabular}

\section{Results}

Out of the total number of patients (421) harboring different types of specific IgE antibodies $60(14.25 \%)$ patients were found to have specific IgE antibodies

against hen's egg and chicken meat. The majority of the patients $56(93.3 \%)$ were children of either equal to or less than 11 years of age. Fig 1 shows data regarding the clinical presentation of the group of 60 patients. 
Fig. 1 Clinical presentation of patients harboring specific IgE antibodies against hen's egg and chicken meat.

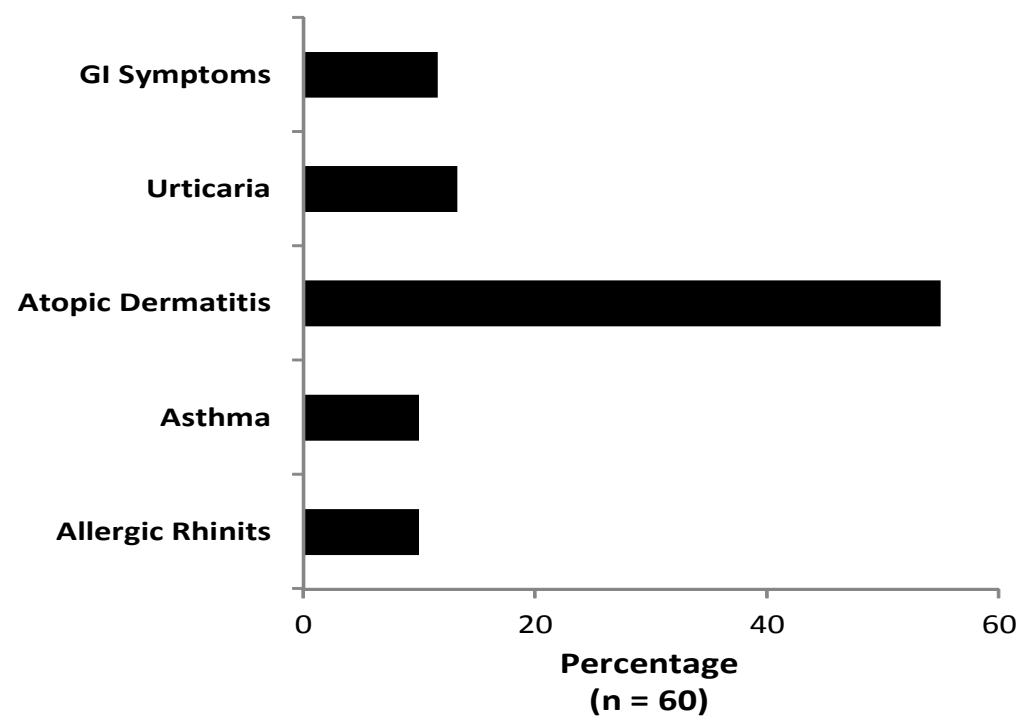

Atopic dermatitis was the most common (55\%) condition that patients presented with and this was followed by urticaria $(13.3 \%)$, gastrointestinal symptoms $(11.6 \%)$, asthma $(10 \%)$ and allergic rhinitis (10\%). Among the 60 patients harboring high levels of egg white and/or yolk specific IgE antibodies 58 (96.6\%) patients had

egg white specific $\operatorname{IgE}$ antibodies whereas 37(61.6\%) patients had egg yolk specific IgE antibodies. Both the antibodies coexisted in 35 patients. Fig 2 describes the distribution of RAST scores for specific IgE antibodies against the hen's egg white, yolk and chicken meat among the patients.

Fig. 2 Radioallergosorbent test (RAST) scores of specific IgE antibodies against hen's egg white, yolk and chicken meat in 60 patients presenting with various allergic disorders.

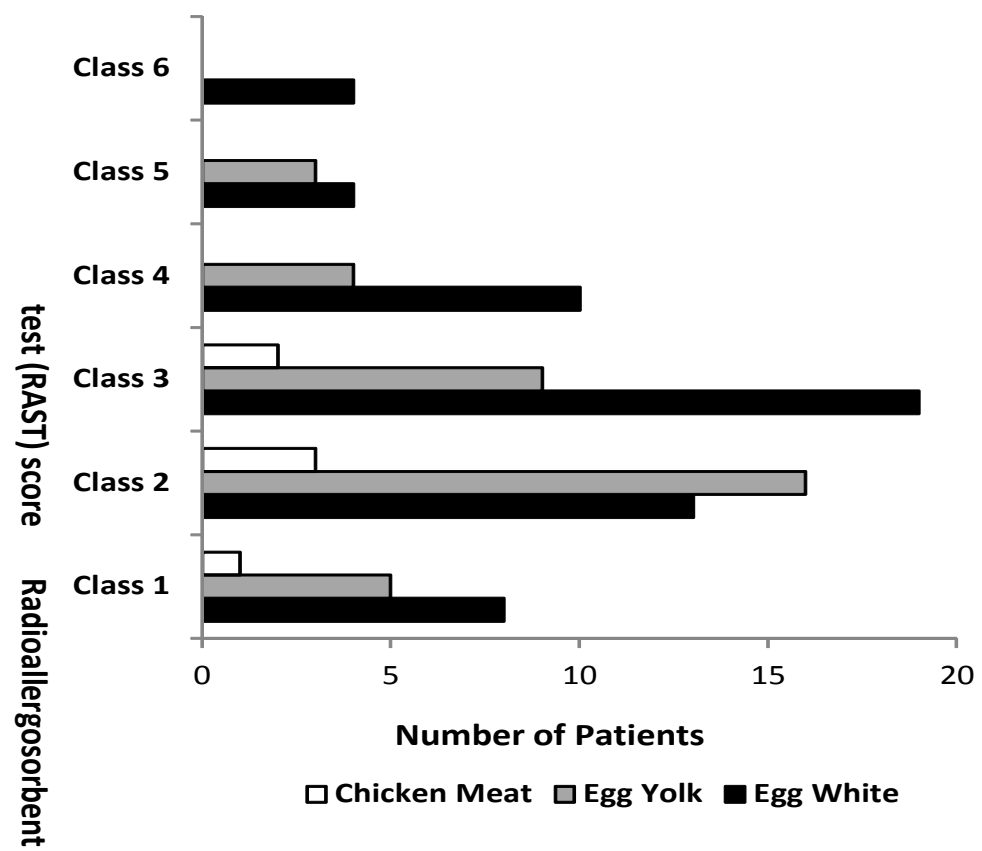


Based on the RAST scores for $\operatorname{IgE}$ antibodies against egg white class 3 was found in 19 patients and this was followed by class 2 in 13, class 4 in 10, class 1 in 8 , class 5 in 4 and class 6 in 4 patients. Similarly for specific $\operatorname{IgE}$ antibodies against the egg yolk class 2 RAST score were observed in 16 patients which was followed by class 3 in 9 , class 1 in 5 , class 4 in 4 and class 5 in 3 . None of the patients had class $6 \mathrm{IgE}$ levels for egg yolk. Specific IgE antibodies against the chicken meat were found only in 06 patients where RAST score class 2 was found in 3 , class 3 in 2 and class 1 in one patient only. In four patients high levels of specific IgE antibodies against the egg white, yolk and chicken meat were detected simultaneously whereas in 2 patients only chicken meat specific $\mathrm{IgE}$ antibodies were present. Fig 3 describes data of other food specific IgE antibodies detected among patients harboring specific IgE against egg white, egg yolk and hen's meat. The most frequently detected antibodies were sIgE antibodies against milk (68.3\%) followed by peanut $(51.6 \%)$, wheat $(33 \%)$, sesame seeds $(17 \%)$ and banana $(10 \%)$ in descending order.

Fig.3 Frequency of other food specific IgEs present in patients harboring specific IgEs against hen's egg and meat $(n=60)$.

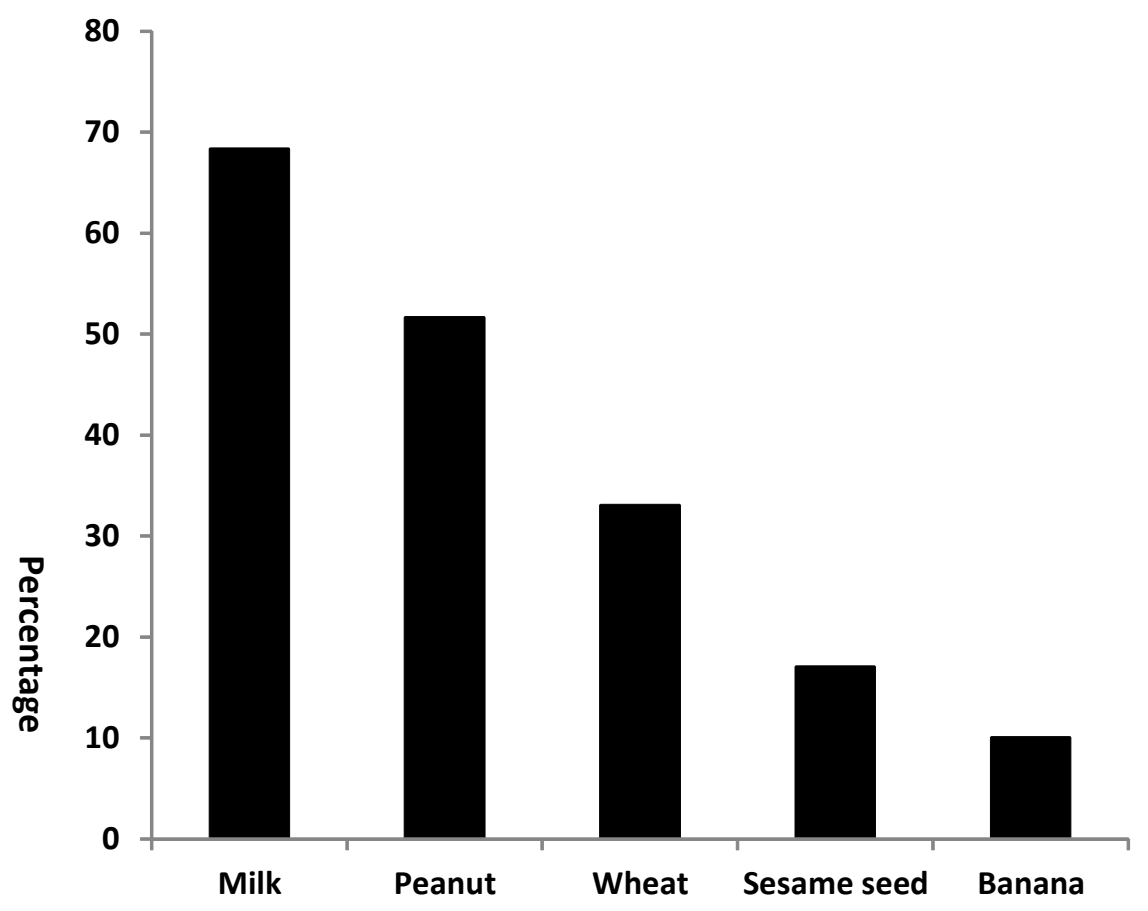

\section{Discussion}

Patients with atopic dermatitis were in majority among the allergic disorders who were found to have high levels of specific IgE antibodies against hen's egg and chicken meat. Whereas specific IgE antibodies were frequently detected against hen's egg $\operatorname{IgE}$ antibodies against chicken meat were not common. In the present study $14.25 \%$ of the patients were found to have high levels of hen's egg specific IgE antibodies. In a relatively smaller number of patients a recent study investigating food allergies in children by skin prick tests and detection of specific $\operatorname{IgE}$ in sera, egg allergy was detected in $23.7 \%$ of the patients which was highest among the other allergies.13 Similarly, in children with the con- 
firmed diagnosis of food allergy 20.1\% were found to be allergic to hen's egg.14 Higher detection rates of egg specific IgE antibodies may not represent the actual prevalence rates in the community as many studies including the present study were performed among patients with only relevant history and clinical presentation of specific allergic conditions not supported by other confirmatory investigations. This could possibly explain the remarkably low $(1.6 \%)$ prevalence of egg allergy previously reported among three year old children in a study performed in unselected population of adults and children by skin prick test, specific IgE detection, histamine release test and food challenge. 7

Among the patients with RAST positive for hen's egg specific $\operatorname{IgE}$ antibodies strikingly high proportion of patients $(96.6 \%)$ in the present study had specific $\operatorname{IgE}$ antibodies against egg white. This may be due to several allergens such as ovalbumin, conalbumin, ovomucoid and lysozyme present in the egg white. These allergens are known for their potential to cause food hypersensitivities in children and adults.15 Diagnostic utility of serum levels of specific IgE against egg white has been evaluated and it was recommended that a level of $1.3 \mathrm{kU} / 1$ corresponding to RAST score 2 or above does not require additional investigations to establish the diagnosis of egg allergy.16 A study investigating wheezing children has shown that RAST test score of 1 and above for specific IgE against egg white is significantly associated with later development of asthma.17 Although this observation appears to be relevant in context of patients with clinical evidence of allergic disorders the presence of high levels of specific $\operatorname{IgE}$ in asymptomatic individuals may also serve as a useful indicator for future development of allergic diseases. In addition, the serum levels of specific $\operatorname{IgE}$ antibodies against egg white are believed to be influenced by persistent exposure to the allergen. Elimination of egg white from the diet of children known to harbor high levels of specific IgE antibodies has been shown to be associated with significant reduction in the serum levels of specific IgE antibodies.18 Avoidance of allergen exposure may therefore appears to be a useful strategy for the reduction of disease manifestations particularly among patients sensitized against egg white.

Although less than the egg white $61.6 \%$ of the patients in the present study had high levels of specific $\operatorname{IgE}$ antibodies against the hen's egg yolk. Presence of high levels of specific $\mathrm{IgE}$ antibodies against egg yolk has been proposed to be a risk factor for atopic dermati- tis.19 Majority of the patients in the present study were suffering from atopic dermatitis and the presence of high levels of yolk specific $\operatorname{IgE}$ antibodies may be of significant relevance. In a recent study $28 \%$ patients with confirmed diagnosis of egg allergy were found to be sensitized against egg yolk. It was however observed that comparatively higher concentrations of egg white specific $\mathrm{IgE}$ antibodies were present in patients who were displaying additional sensitization to egg yolk.20 This finding indicates an association between egg white and egg yolk specific IgE antibodies. A study investigating food specific $\operatorname{IgE}$ antibodies in patients with atopic dermatitis has clearly demonstrated that egg white specific IgE antibodies correlate with egg yolk specific $\mathrm{IgE}$ antibodies in these patients.19 It is therefore possible that the coexistence of egg white and yolk specific $\operatorname{IgE}$ antibodies in a significantly higher proportion of patients in the present study was probably due this undetermined association between the two types of antibodies.

Whereas hen's egg specific IgE antibodies were present in the majority of the patients in this study a very small fraction of patients had chicken meat specific IgE antibodies. Despite extensive consumption of chicken meat there are few published data regarding allergic reactions to chicken meat. In children with atopic dermatitis $17 \%$ of the patients reacted positively to chicken meat. This proved to be of no clinical relevance as the same population of children when challenged with chicken meat only 2\% reacted. 21 Chicken meat has been reported to be implicated in oral allergy syndrome with high serum levels of chicken meat specific $\operatorname{IgE}$ antibodies. 22 In another case report angioedema due to chicken has also been reported where the patient had specific $\operatorname{IgE}$ antibodies to chicken meat and egg yolk.23 In addition the presence of chicken meat specific $\operatorname{IgE}$ antibodies without coexisting egg specific IgE have been implicated in allergic asthma and induction of local and general symptoms of food allergy.24,25

Patients harboring hen's egg and chicken meat specific $\mathrm{IgE}$ antibodies were also found to have other food specific IgE antibodies against milk, wheat, peanut and sesame seeds in higher proportions. A vast majority of children suffering from atopic dermatitis have been found to have a positive skin prick test reactivity to one or more food allergens such as egg, milk, wheat, peanut, fish, soy and potato26,27 An investigation among patients with atopic dermatitis involving skin prick testing, detection of food specific IgE antibodies and allergen 
challenge has clearly demonstrated that the most common foods associated with persistent lesions are egg, milk and peanut28. The findings of the present study and the existing evidence indicate that sensitization against egg if not as a single allergen may have role in atopic dermatitis in conjunction with other sensitizing food materials.

\section{Conclusion}

Majority of the patients in the present study were suffering from atopic dermatitis and had high levels of specific IgE antibodies against hen's egg. Although specific $\operatorname{IgE}$ antibodies other food materials were also detected in the patients included in the present study it is difficult to establish a direct link between the presence of hen's egg and chicken meat specific IgE antibodies with atopic dermatitis. A large scale prospective study is recommended to further evaluate egg allergy in the local population by inclusion of specific investigations to determine the prevalence rates of hen's egg and chicken meat allergy and its clinical manifestations.

\section{References}

1. Sampson HA: Update on food allergy. Quiz 20. J Allergy Clin Immunol 2004; 113: 805-19.

2. Sampson HA. Atopic dermatitis. Review. Ann Allergy 1992; 69: 469-479.

3. Hoffman DR, Yanamoto FY, Sellar B, Haddad Z. Diagnosis of $\mathrm{IgE}$ mediated reactions to food antigens by radioimmunoassay. Clin Immunol 1975; 55: 256267.

4. Sampson HA, Scanlon SM. Natural history of food hypersensitivity in children with atopic dermatitis. J Pediatr 1989; 115: 23-27.

5. Pasternack B. The prediction of asthma in infantile eczema. J Pediatr 1965; 66: 164-165

6. Stifler WC. A twenty-one year follow-up of infantile eczema. J Pediatr 1965; 66: 166-167.

7. Osterballe M, Hansen TK, Mortz CG, Host A, Bindslev-Jensen $\mathrm{C}$. The prevalence of food hypersensitivity in an unselected population of children and adults. Pediatr Allergy Immunol 2005; 16: 567-573.

8. Allen CW, Campbell DE, Kemp AS. Egg allergy: are all childhood food allergies the same? J Paediatr Child Health 2007; 43: 214-218.

9. Allen CW, Kemp AS, Campbell DE. Dietary advice, dietary adherence and the acquisition of tolerance in egg-allergic children: a 5-yr follow-up. Pediatr Allergy Immunol 2009; 20: 213-218
10. Everberg H, Brostedt P, Oman H, Bohman S, Moverare R. Affinity Purification of Egg-White Allergens for Improved Component-Resolved Diagnostics. Int Arch Allergy Immunol 2011; 54: 33-41.

11. Amo A, Rodriguez-Perez R, Blanco J, Villota J, Juste $\mathrm{S}$, et al. Gal d 6 is the second allergen characterized from egg yolk. J Agric Food Chem 2010; 58: 7453-7457.

12. Cahen YD, Fritsch R, Wüthrich B. Food allergy with monovalent sensitivity to poultry meat. Clin Exp Allergy 1998; 28: 1026-30.

13. Ferrari GG, Eng PA. IgE-mediated food allergies in Swiss infants and children. Swiss Med Wkly 2011; 12: 141.

14. Crespo JF, Pascual C, Burks AW, Helm RM, Esteban MM: Frequency of food allergy in a pediatric population from Spain. Pediatr Allergy Immunol 1995; 6: 39-43.

15. Ratner B, Untracht S. "Egg allergy in children; incidence and evaluation in relation to chick-embryopropagated vaccines. AMA Am J Dis Child 1952; 83: 309-316.

16. Diéguez MC, Cerecedo I, Muriel A, Zamora J, Abraira V, Camacho E et al. Utility of diagnostic tests in the follow-up of egg-allergic children. Clin Exp Allergy 2009; 39: 1575-84.

17. Kotaniemi-Syrjänen A, Reijonen TM, Romppanen J, Korhonen K, Savolainen K, Korppi M. Allergen-specific immunoglobulin $\mathrm{E}$ antibodies in wheezing infants: the risk for asthma in later childhood. Pediatrics 2003; 111: e255-61.

18. Fadeeva T, Asin JL, Horrillo ML, Baraut TG, Vela RF, Conde SL et al. Results of the oral egg-challenge test performed on two different groups of children. One group with a history, suggestive of allergic reaction with egg intake and the other group sensitized to hen's egg without previous egg intake. Allergol Immunopathol 2010; 38: 233-40.

19. Lo YC, Yang YH, Chiang BL. Food-specific immunoglobulin $\mathrm{E}$ among children with atopic dermatitis: a retrospective study. J Microbiol Immunol Infect 2005; 38: 338-42.

20. Egger M, Alessandri C, Wallner M, Briza P, Zennaro D, Mari A et al. Is aboriginal food less allergenic? Comparing IgE-reactivity of eggs from modern and ancient chicken breeds in a cohort of allergic children. PLoS One 2011; 6: e19062.

21. Sampson HA. The role of food allergy and mediator release in atopic dermatitis. J Allergy Clin Immunol 1988; 88: 735-745

22. Vila L, Barbarin E, Sanz ML. Chicken meat induces oral allergy syndrome: a case report. Ann Allergy Asth- 
ma Immunol 1998; 80(2): 195-6.

23. Martínez Alonso JC, Domínguez Ortega FJ, Fuentes Gonzalo MJ. Angioedema due to sensitization to chicken meat [Article in Spanish]. Allergol Immunopathol 2003; 1: 50-2.

24. Gonzalez-de-Olano D, Bartolome B, Maroto AS, Vivanco F, Pastor-Vargas C. Asthma after chicken consumption due to cross-reactivity between fish and chicken parvalbumin.

J Investig Allergol Clin Immunol 2012; 22: 227-8. 25. Kuehn A, Lehners C, Hilger C, Hentges F. Food allergy to chicken meat with $\mathrm{IgE}$ reactivity to muscle alpha-parvalbumin. Allergy 2009; 64 :1557-8. doi: 10.1111/j.1398 9995.2009.02094.x

26. Johnke H, Norberg LA, Vach W, Host A, Andersen KE. Patterns of sensitization in infants and its relation to atopic dermatitis. Pediatr. Allergy Immunol 2006; 17 : 591-600.

27. Rennick GJ, Moore E, Orchard DC. Skin prick testing to food allergens in breast-fed young infants with moderate to severe atopic dermatitis. Australas. J. Dermatol 2006; 47: 41-5.

28. Eigenmann PA, Calza AM. Diagnosis of IgE-mediated food allergy among Swiss children with atopic dermatitis. Pediatr Allergy Immunol 2000; 11: 95-100. 